\title{
Research on the Application of Computer Music Production in College Music Teaching
}

\author{
Wei Zhiqiang \\ Academy of music, Nanyang Institute of Technology, Nanyang, 473004, China \\ email: 45542506@126.com
}

Keywords: Computer music production, College music teaching, MIDI, Audio technology

\begin{abstract}
Music teaching plays an important role in quality education, which could not only improve students' artistic attainment and cultural quality, but also their professional skills. The nature of teaching computer generated music production technology requires consensus of audio and visual experience. Recently, computer has become a necessary teaching instrument, which combines computer technology with music. Applying computer generated music production technology to music teaching process could improve music teaching situation as well as filling in the gaps in traditional prdagogy, by which both the teaching quality and students' learning interests could be improved. Computer generated music production technology is significant in teaching composition, harmony, orchestration, singing and playing musical instrument. This paper mainly focuses on analyzing the related application of computer generated music production technology in music teaching process.
\end{abstract}

\section{Introduction}

With the development of the science and technology, computer technology in a growing number of knowledge areas has been widely used[1]. The computer music technology, embodying the blend crystallization of science and art makes music taking a qualitative change in the creation, playing, dissemination and other aspects[2]. From the perspective of music education, the computer can almost infiltrate the area in which traditional music can be involved. Meanwhile, the current computer has a powerful practical function which can provides a new broad stage for the development of traditional music[3]. The composer can use the computer music technology, professional music software, more and better audio material and a variety of soft sound source and music creation techniques to create their own satisfied music works conveniently for obtaining the expected music effect.

In the 21st century music life, there have been some professional people specialized in the operation of computer music or music performance, that is, computer music producers and computer musicians[4]. They broke through the inherent model of playing traditional instruments, making the human body function and musical instrument physical properties are no longer limited. In addition, computer music can produce the sound which natural does not exist, and create, expand and enrich the sound effects and means of expression which the ordinary instruments can not show[5]. The continuous development of computer music technology makes great changes have taken place in the process of traditional music creation, changing the way of music creation and transmission of thousands of years. The creation, performance and production are transferred in a furnace, and the composition, instruments, playing, command and the recording are melted as a whole, which realizes the unity among the imagination of the composer and music producer, the skills of players and perfect listening[6]. It has a special meaning and function in improving and enriching the quality and quantity of music creation and performance, simplifying the process of music making, reducing the cost of music transmission and improving the efficiency of the spread of music. Based on this, this paper intends to give the analysis and research on the significance of computer music production technology in music teaching, its multi - dimensional application, and the influence on teaching. 


\section{The Significance of Computer Music Production in College Music Teaching}

In music teaching, the application of computer music production technology is based on the computer technology, with the control technology and control information used in the production technology of musical Instrument Digital Interface (MIDI), audio technology and music production technology as the support, and the musical instrument as an audio terminal music production information technology. Computer music production as a new combination of theory and practice of comprehensive curriculum has its main features: practicality and applicability, specifically in the following three aspects: First, MIDI production technology; Second, audio technology; Third, music production. These three are closely linked.

First of all, from the perspective of current situation of college music theory teaching to analyze, there is a close link between computer music production technology and music teaching, which belongs to the interdependent relationship. Computer music production technology as a new type of teaching methods, applied to the traditional music teaching, can improve the teaching efficiency of music theory courses, sound instrument music singing courses and computer practice application course. In the existing music teaching, students want to master the computer music production technology. First of all, they need to have a certain knowledge of music theory to create and produce music, and the traditional music teaching contains music professional theory and technical skills knowledge. However, the music theory and technical skills are of diversity and complexity, only in the long study and research will achieve some success. In the study of music theory knowledge, the traditional learning method can not really experience and practice, which is only a theory and the book of knowledge and will not receive a good teaching effect. The application of computer music production technology realizes the music theory teaching innovation, the combination of theory and practice operation, which helps to stimulate students' interest in learning and promote the improvement of teaching quality and teaching level. The change of teaching method of music theory course also promotes the promotion and optimization of computer music production technology, so these two are mutually reinforcing and mutually reinforcing.

Secondly, in the music teaching, the application of computer music production technology can significantly improve the teaching effect. When the computer information technology is not applied in the teaching of the theory of music major, the traditional teaching methods such as the blackboard and the teaching method show only the professional teaching knowledge and music scores, so that the students can not really feel the specific sound effect. The application of computer music production technology in music teaching can form a system of music production process which includes the whole process of music, harmony, polyphony, playing, singing, production, recording. In the process of music production, a wealthy computer functions and technology are used, and many necessary elements of music production are added. In the music teaching in colleges, the application of computer music technology has promoted the reform of music theory teaching and changed the traditional music creation methods, which satisfies the requirements of quantity and quality of music production. It can be said that the application of computer music production technology in music teaching in colleges is a kind of reform of music teaching, and is also the embodiment of the current spirit of education and teaching innovation, which greatly promoted the improvement of teaching quality.

In addition, in music teaching, computer music production technology has multi-dimensional application value. First, the music effects can be produced by the computer music production technology. Second, the computer music production software can play the effect of the function at any time. Fourth, computer music production technology has auditory, visual and other functions, which achieve the auditory and visual synchronization teaching. Fifth, the computer has a good running speed, and the operation is accurate. Sixth, the computer music production software can achieve the performance and the spectrum of the conversion function, that is, the MIDI signal is converted into music. On the contrary, the music can also be used to show the actual sound effects of different instruments, at any time to correct, real-time feelings, effectively stimulate students' interest in learning and improve learning efficiency.

Based on the above teaching effect, this paper believes that the use of computer music 
production in the teaching of computer music teaching can improve the deficiencies of the traditional music teaching, not only to stimulate the enthusiasm of students to learn, but also to improve the quality of teaching effectively.

\section{The Characteristics of Computer Music Production in College Music Teaching}

With the development of computer technology and a wide range of applications, in music teaching and production, more and more teachers and music producers choose to use the computer for music teaching and music production. In addition, the characteristics and advantages of computer music production in teaching are shown in Fig.1.

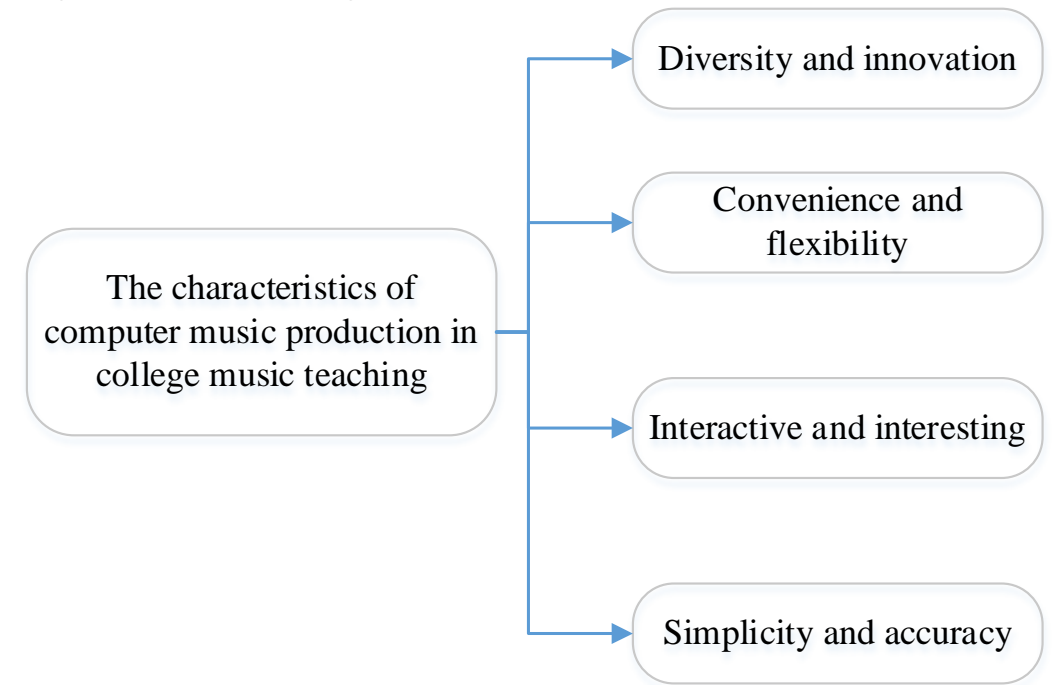

Fig 1. The characteristics of computer music production in college music teaching

Diversity and Innovation. In the computer music production technology, a variety of music production software make computer music production technology presents diversity. Different music software can show different advantages and functions, but also showing a different musical effects, even the same class of music software, in the actual operation, the appropriate changes and adjustment can also achieve different auditory effects.

Convenience and Flexibility. In music teaching, the production and application of computer music production software technology simplifies the traditional music production and teaching work, so students can make music creation and MIDI production in any place (such as bedroom, classroom, etc.) only by a computer. In the implementation of teaching process, teachers can make a creation in blackboard or other teaching methods, which can save a lot of time on the blackboard and improve student learning efficiency.

Interactive and Interesting. In music teaching, the interactive characteristics of computer music production, both for students and teachers, have a positive meaning, not only to promote students to actively think, stimulate interest in learning, but also improve the quality of teaching. Although computer music production provides a wealth of interactive teaching content, but we still have to emphasize the analysis of specific circumstances, that is, according to the teaching object of the interactive differences in time to be able to seize the teaching of interactive opportunities, so that students actively participate in classroom teaching.

Simplicity and Accuracy. Through the computer, teachers can let teachers in a relatively short period of time to judge the problems in teaching, quickly add the relevant music knowledge and timely adjustment of teaching content, to find out the points of interest of students and targeted teaching. At the same time, computer music production technology can correct the errors in the students music production through some procedures.

In short, the application of computer music production technology in the teaching of music theory can make the effective interaction between students and teachers more concisely and accurately, so as to connect and integrate teachers with students' aesthetic search. This reason also provides a very flexible space for teachers to explain, that is, in this rational space, teachers should 
become a rational terminal, to fully control and play the computer music technology can achieve the teaching objectives, appreciation goals and creative goals.

\section{The Multidimensional Application of Computer Music Production in College Music Teaching}

Computer music production, as a tool and method of teaching and performing practical skills in music in today's music life, can combine images, sound, score and so on, and make training for students in composing, singing, playing and so on, which can help students to improve the creative skills of music creation, shown in Fig 2.

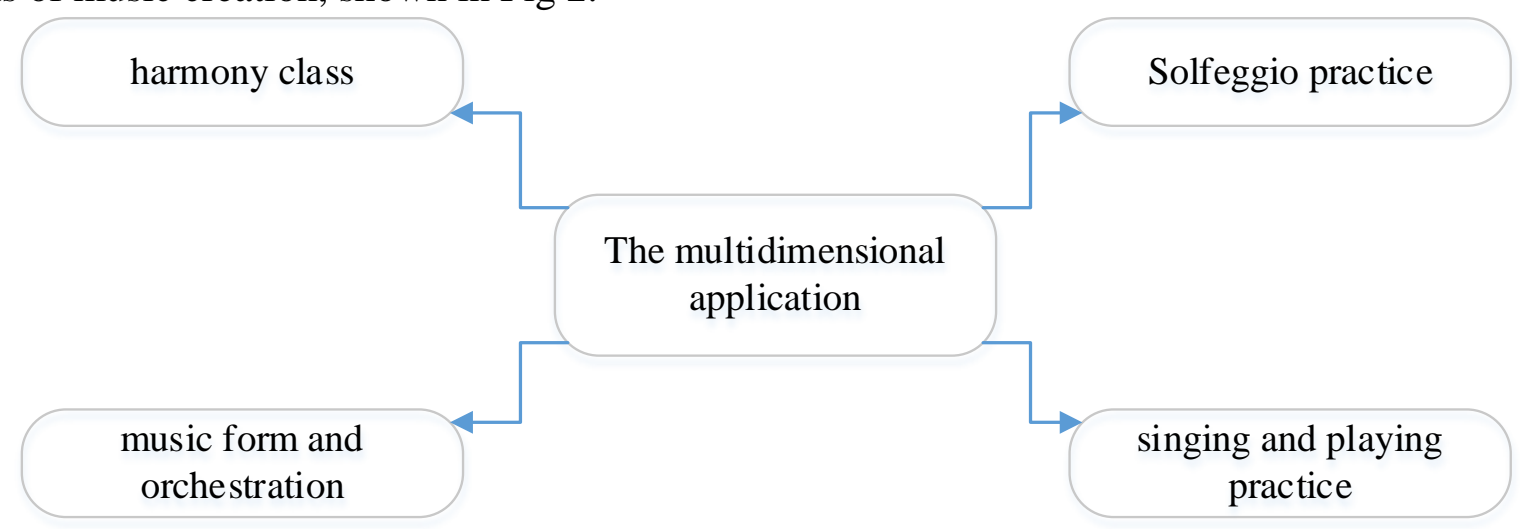

Fig 2. The multidimensional application

The Application in Harmony Class. In the teaching of music theory, how to apply the computer music production technology in the harmony course teaching is the practical need of the curriculum. Thus, the computer music production technology can maximize the advantages of computer technology, enhance the vividness of music theory and harmony teaching, and then make up and improve the traditional music theory teaching problems. Restricted by audio and piano levels, teachers are difficult to present the sound and harmony effects to students. Moreover, in the process of learning harmony knowledge, students can only master the harmony effect through rote memorization. Therefore, the application of computer music production technology in harmony music teaching, can transfer the knowledge composition, principles and definitions which are difficult to understand into the simple and concrete sound effects. In addition, it can mobilize students' music learning enthusiasm and interest, improve the quality of harmony teaching and achieve the desired purpose of the desired effect.

The Application in the Practice of Solfeggio. In the teaching of the basic theory of music, the solfeggio course is a comprehensive course for teaching and training students' pitch and rhythm. In the training, according to the needs of the course, teachers can use the computer music production technology to design training in different difficulty, different speed, different length of the melody and rhythm. The application of computer music production technology is easy for teachers to compose the teaching content, reduce the difficulty of work, improve the level of students' practice, improve teaching efficiency, and effectively improve the deficiency of traditional music theory teaching.

The Application in Music Form and Orchestration. In the traditional music teaching, teachers are affected by the teaching equipment and restrictions. So students can only feel some of the music works in the sound, and it is difficult for students to have a comprehensive, specific feelings on the music. The application of computer music production technology in the college music teaching can make use of computer music production technology, analyze music works, and give a special explanation and display for each of them: structure, rhythm, melody and other detailed analysis. So that students can really master the essence of music, feel the charm of music and enhance theirs interest in music and learning enthusiasm. In the teaching of music theory, teachers use computer music production technology to enter a piece of music, and deal with the music. So that students cam learn to listen, learn music appreciation and composer method. In the music creation, the orchestration is a technically strong course. Through the computer music production technology 
application, students can make concrete sound analysis in different instruments, which can make the classroom teaching full of vivid, and promote the quality of teaching.

The Application in Practical Operation of Singing and Playing. In the practice of highly vocal music, instrumental music teaching, students often can not feel their own problems in singing and playing. And it is possible for students to be stuck in a misunderstanding. It is due to the lack of feedback between the singing and audience effect. In this regard, the computer music production technology can be used to help students timely detect their own problems, make up for deficiencies and improve skills and practice level of operation through the production and recording.

For students who study vocal and instrumental specialties, through applying computer music production technology, on the one hand, they can experience and look for the sound effects in concert hall. On the other hand, they can find the deficiencies in singing or playing and and timely correct them. For students who study composer, before the formation of the final synthesis effect, they can timely modify and adjust the work to quickly raise the level of writing. For the students who study recording, they can improve the level of practice through the recording, and accumulate music recording technology experience.

\section{Conclusion}

With the development of society, the school education system is also undergoing constant historical evolution through the reform and reflection. The 21st century Chinese university education has been developed by the traditional teacher classroom teaching for the student-centered teaching. And the whole society has fully realized the the importance of students in the teaching status and knowledge building. In the teaching of music in colleges, modern teaching techniques and teaching methods are widely used. The traditional music teaching mode is gradually changing. The current application of multimedia and computer music production technology in college music teaching improves the teaching effect and breaks some of the limitations in traditional music teaching. It allows students to learn music knowledge and appreciate the charm of music through natural teaching methods. The application of computer music production technology has realized the combination of scientific force and teaching power, effectively played the role and advantage of science and technology in teaching, improved the interest and enthusiasm of students, promoted the reform and development of music theory teaching. With the development of science and technology, the combination of scientific and technological strength and teaching power will be deepened. Some scientific research achievements related to computer music production teaching will be transformed into practical teaching, and the two-way effect will be realized.

\section{References}

[1] Chen Baoli. Research of computer music technology development and teaching practice[J]. Journal of Jiamusi Education Institute, 2013, 133: 74.

[2] Yang Lixia. Applying computer-aided music making to the teaching of music composing[J]. Journal of Jimei University, 2005, 6(4): 90-92.

[3] Yi Le. The necessity for improving and popularizing composition software in music composition instruction at college[J]. Journal of Hainan Normal University, 2009, 2(22): 163-165.

[4] Chen Hang. An artisan hoping to do fine work must first sharpen his tools--The application of computer music technology in higher music education[J]. Journal of Yulin Normal University, 2012, 33(4): 146-150.

[5] Wang Zeling. Applications of computer music to music education in institutions of higher learning[J]. Journal of Guizhou Normal College, 2011, 27(4): 59-62.

[6] Zhang Jiaohua. Application of multi-media approach in solfeggio teaching in colleges[J]. Journal of Guilin Normal College, 2008, 22(1): 126-127. 